\title{
Bladder Cancer in Iran: Geographical Distribution and Risk Factors
}

\author{
Tohid Jafari-Koshki, ${ }^{1,2}$ Shahram Arsang-Jang, ${ }^{3,4}$ and Behzad Mahaki ${ }^{4,}$ \\ ${ }^{1}$ Department of Biostatistics, School of Health, Kermanshah University of Medical Sciences, Kermanshah, IR Iran \\ ${ }^{2}$ Department of Statistics and Epidemiology, Faculty of Health, Tabriz University of Medical Sciences, Tabriz, IR Iran \\ ${ }^{3}$ Department of Biostatistics and Epidemiology, Faculty of Public Health, Qom University of Medical Sciences, Qom, IR Iran \\ ${ }^{4}$ Department of Biostatistics and Epidemiology, School of Health, Isfahan University of Medical Sciences, Isfahan, IR Iran \\ "Corresponding author: Behzad Mahaki, Department of Biostatistics and Epidemiology, School of Health, Isfahan University of Medical Sciences, Isfahan, IR Iran. E-mail: \\ behzad.mahaki@gmail.com
}

Received 2016 February 03; Revised 2016 May 02; Accepted 2017 February 11.

\begin{abstract}
Background: To study overall and province-specific trends of bladder cancer incidence in Iran during 2004-2008 and to evaluate the association between bladder cancer incidence and some factors.

Methods: Data on 17792 bladder cancer patients and risk factors available at province level were used in Bayesian ecological setting. First, the overall and province-specific trends of risk were estimated. Then the effects of cigarette smoking, being overweight, fruits and vegetables consumption, and low levels of physical activity on trend were examined. The province-specific effects of significant factors were also assessed. The data were analyzed using R-INLA package.

Results: The risk of developing bladder cancer was decreasing in Iran, 2004 - 2008 ( $R R=0.95)$. Guilan and Semnan had the highest 5-year incidence (RR > 1.5). However, the risk increase compared to country Risk was the highest in East Azerbaijan and Tehran (DT > 0.1). Also direct and reverse association between smoking and fruit consumption and bladder cancer risk were established. Guilan, Semnan, Sistan and Baluchestan, and Ilam were the provinces affected the most by these factors.

Conclusions: This study confirms previous findings and provides further evidence on protective effects of fruit consumption in bladder cancer. The results would be of value for governors to prioritize the province-specific demands on research, education, and improvements with respect to the identified risk factors.
\end{abstract}

Keywords: Bladder Cancer, Disease Mapping, Spatiotemporal, Ecological, Risk

\section{Introduction}

Bladder cancer (BlCa) is the sixth most common cancer and ninth cause of death due to cancer worldwide. Lung and bladder cancers in males are most frequent cancers in the Eastern Mediterranean Region, and sixth most common cancer in Iran with estimated age-standardized incidence rate (1) of 8.4 per 100,000 population and ranks the second cancer site among Iranian males (2). It also is the major genitourinary cancer with ASR increasing from 2.12 in 2003 to 3.28 in 2009 (3). BlCa is important with regard to the high medical costs and its impact on the patients' quality of life (4). Although its treatment costs exceed all other types of cancer, these treatments extend the time to recurrence, not the survival (5). These highlight the merits of studies aiming for BlCa prevention.

Smoking is recognized as the most prominent risk factor for BlCa for about $50 \%$ of cases in developed countries (6).

Vegetable and fruit intake are amongst the disputable factors to possess protective roles in BlCa incidence (7). In a study conducted across European countries, no clear relation between a varied fruit and vegetable consumption and BlCa risk was reported (8).
Excessive body mass index (BMI) and low level of activity are other controversial risk factors with reported effect of little to none in relation to $\mathrm{BlCa}(9)$.

Standardized incidence/mortality rates (SMR) summarize the spatial information on a map and help policy makers to detect areas with high and low risks (10). However, they usually violate the theoretical assumptions and do not take the spatial correlations into count and therefore, may be misleading (10-18).

Here we used a method in a hierarchical Bayesian framework to overcome these problems and obtain better and less dispersed estimates of relative risk (RR) (19). The potential correlation among neighboring areas is introduced to the model by using a conditional autoregressive (CAR) Normal distribution. Adding the explanatory variables to the model not only gives the adjusted RR in areas, but also enables evaluating the impact of each covariate on RR of developing BlCa.

Despite being subject to bias, ecological studies have several merits such as being inexpensive and convenient, producing better estimates of less dispersed variables by covering much wider area, and alleviating measurement error problems (20). And under certain conditions, their results are likely to emerge in individual levels (21). 
BlCa is one of major cancers in Iran, especially among men. However, previous studies about BlCa incidence trends in Iran are at province level (22). Also studies with the focus on risk factors are case-control (23). There is no study on BlCa and its risk factors in Iran with a focus on both incidence trends and risk factors using spatiotemporal models. The aim of present study was to study trends and spatial patterns of BlCa incidence in Iran, 2004 -2008, as well as to investigate some factors potentially associated with the incidence.

\section{Methods}

We used the data for bladder cancer (ICD10 code C67) for 2004 - 2008, made available by The Iranian ministry of health and medical education. The existing risk factors at province level that we evaluated are as follows. BMI $>$ 25: population percentage with body mass index $>25$; cigarette: Average number of cigarette smoking per day; Fruit: portions of fruit consumption per day; vegetables: units of vegetable consumption per day; Low activity: population proportion with low levels of activity defined as activity with $<600$ metabolic equivalent tasks-minute (METminute) per week. Since these data were available for 2006 -2008, we assessed the trends by fitting the model without covariates from 2004 to 2008 , and examined the risk factors by using data for 2006 - 2008.

The used model has two key features. First, in addition to assuming an uncorrelated structure which is inherent in each area due to variations in individuals, it estimates RR by using CAR distribution for neighboring areas. Second, it has additional parameters to capture the overall time effect and assess province-time interaction. The model including covariates will estimate the covariate effects and will give an adjusted estimate of risks in each region. Formally, this model is defined as follows. Let i denote ith area, or the province in our study, and t be the year indicator. Assume a Poisson distribution for observed number of events in province $\mathrm{i}$ and year $\mathrm{t}, \mathrm{O}_{\mathrm{it}}$. Then the corresponding relative risk in log scale, i.e. $\log \left(R_{\mathrm{it}}\right)$, can be modeled via the linear predictor below.

$O_{i t} \sim$ Poisson $\left(E_{i t} \times R R_{i t}\right)$

$\log \left(R R_{i t}\right)=\alpha+u_{i}+v_{i}+\sum_{j=1}^{J} \beta_{j} \times x_{i j t}+\beta \times t+\delta_{i} \times t$

Where $E_{i t}$ is the expected number of cancer cases for province " $\mathrm{I}$ " in year $\mathrm{t}, \alpha$ is overall relative risk, and $\mathrm{u}_{\mathrm{i}}$ and $\mathrm{v}_{\mathrm{i}}$ introduce the uncorrelated and correlated heterogeneity, respectively. Parameter " $\beta$ " allows for overall time effect and $\delta_{\mathrm{i}}$ imply province-specific effect of time, so-called differential trend (DT). A Normal prior distribution is assumed for $\mathrm{u}_{\mathrm{i}}$. Also, $\mathrm{v}_{\mathrm{i}}$ and $\delta_{\mathrm{i}}$ are assumed to follow CARNormal distributions. $\mathrm{x}_{\mathrm{ijt}}$ indicates the $\mathrm{jth}$ covariate value for year $t$ in province $i$ with corresponding coefficient $\beta \mathrm{j}, \mathrm{j}$ $=1, \ldots, \mathrm{J}$.

Cumulative risk during the period under investigation was obtained by fitting BYM model (24). The BYM model has no parameter to capture the main or interaction effect of time and gives cumulative RR by treating the whole period as a single time point. To fit this model, we used totally observed and expected new cases over 5 years. We also used varying slope model to estimate province-specific coefficients for covariates of the final model by using a CARNormal distribution (25).

R-INLA package, available at www.r-inla.org, was used to fit all models (26). This package uses Laplace approximations to produce the posteriors of the parameters. Model adequacy statistics are provided as well. Since R-INLA does not use Markov chain Monte Carlo (MCMC) methods, it is fast and the model convergence is not an issue (27). Here, mean deviance (Mean Dev.), deviance information criteria (DIC), effective number of parameters (pD), and the logarithmic score (LS) were used to choose the best model (27). Smaller values for these criteria are desirable and a model with a better trade-off between model fit and complexity will be considered as the best one possble. In significance tests, the null hypothesis is rejected if 95\% Bayesian Credible interval (CrI) does not include the null value.

\section{Results}

There has been a total of 17792 new bladder cancer cases registered during 2004-2008, with the maximum in Tehran (P28: Province with the number 28 on the maps) with 1352 cases in 2008. The results for spatiotemporal model for 2004 - 2008 and 2006 - 2008 are given in Table 1. The trend of incidence significantly decreased for both periods, especially for $2006-2008$.

Table 1. Results for Spatiotemporal Model, 2004 - 2008 and 2006 - 2008, Described as Estimate (95\% CrI)

\begin{tabular}{lcc}
\hline & $\mathbf{2 0 0 4 - 2 0 0 8}$ & $\mathbf{2 0 0 6 - 2 0 0 8}$ \\
\hline Intercept & $-0.121(-0.253,0.009)$ & $-0.133(-0.268,-0.0013)^{\mathrm{a}}$ \\
Time & $-0.022(-0.036,-0.007)^{\mathrm{a}}$ & $-0.087(-0.118,-0.056)^{\mathrm{a}}$ \\
\hline Mean Dev. & 1699.50 & 922.58 \\
\hline DIC & 1751.41 & 975.82 \\
\hline pD & 51.91 & 53.23 \\
\hline LS & 6.98 & 7.13 \\
\hline${ }^{\mathrm{a}}$ Significant at 95\% level. & & \\
\hline
\end{tabular}


RRs estimated from BYM model for 2004 - 2008 (Figure 1A) suggest that the 5-year RR is the highest for Guilan (P9, $R R=1.675)$, Semnan ( $P 26, R R=1.623)$, Isfahan $(P 6, R R=1.488)$, Fars (P7, RR=1.407), Kerman (P29, RR=1.328), Hamadan (P11, $\mathrm{RR}=1.285)$.

Positive/negative value of DT (Figure 1B) implies that the corresponding province has a trend steeper/less steep than the country average trend in 2004 - 2008. The highest temporal trend (TT) estimated for East Azerbaijan (P3), Tehran (P28), and Khuzestan (P19) (Figure 1C).

These results are evident from Figure 2, where the estimated RR is plotted for each year. This figure provides more details on RR and its trend for each province. The gradual lighting of the maps implies the decreasing pattern of BlCa incidence.

Table 2 presents a summary of the measured risk factors in all provinces for each year.

Crude effects of single covariates are shown in Table 3. Smoking and low levels of activity significantly increase the RR, whereas fruit and vegetable consumption have protective effects. The trend is significantly decreasing for all models.

The model including all covariates indicates decreasing pattern for 2006 - 2008, and introduces smoking and fruit as risk and protective factors in developing BlCa, respectively (Table 4).

In a search for the best model, we explored various settings of covariates and reported the results for the model with best trade-off between the model fit (DIC $=949.70)$ and complexity ( $\mathrm{pD}=55.94$, and $\mathrm{LS}=6.89$ ) under the column entitled 'Best model'. The trend is again significantly decreasing for this model. The effect of the covariates in this model is almost the same as the 'Full model'.

According to the results (not fully shown here) of varying slope model for the covariates in the 'Best model', the following provinces are affected the most, in a decreasing order, from smoking with estimated slopes in parentheses: Guilan (P9, 0.053), Semnan (P26, 0.053), Yazd (P29, 0.041), Isfahan (P6, 0.039), and Fars (P7, 0.033). This order for fruit consumption is as follows: Sistan-and-Baluchestan (P27, 1.213), Ilam (P13, -0.924), Hormozgan (P12, -0.566), North Khorasan (P18, -0.542), Zanjan (P30, -0.430), Qom (P25, 0.413), and Kohgiluyeh and Boyer Ahmad (P20, -0.365). These results were the same after adjusting each factor for the other.

\section{Discussion}

In this study, we estimated RRs value for each province and also risk factors of bladder cancer where RR shows risk for an individual of specific province compared to risk of total population of country. Results based on RRs indicated spatial variation in pattern of cancer incidence rate. There was a significant decreasing pattern for the risk of BlCa in Iran during 2004 - 2008. The RRs for $47 \%$ of province were higher than country risk. Also the ecological regression analysis showd that fruit consumption and cigarette smoking were found to be a protective and a risk factor in developing BlCa, respectively. Estimated incidence pattern of bladder cancer is similar to that of developed countries.

The role of smoking in BlCa has been known for decades (28). Reported strength of association is different in studies, with larger estimates from case-control ones (7). It has been reported that cigarette smoking is associated with the risk of BlCa in both sexes (29). Significantly elevated risk of BlCa has been reported in current smokers compared to never smokers with OR $=2.87$ (95\% CI:1.61-5.11) (30). In a study on a large population from European countries, this association was found to be stronger with $\mathrm{OR}=$ 3.96 (95\% CI: 3.07 - 5.09) for current smokers compared to never-smokers (31). A high proportion (66\%) of male BlCa cases has been attributed to smoking (6). According to the comparisons made between the results from a large sample study from 1995 to 2006 and the estimates from cohorts between 1963 and 1987, the elevated risk of smoking was reported to be higher in the more recent cohorts, with population attributable risks for women comparable to those for men (32). The significant relation between cigarette smoking and BlCa has been also confirmed in Iranian population (33). Shared component analysis showed a significant shared effect of smoking on BlCa and other cancers in Iran (15).

We found almost strong association between smoking and risk of $\mathrm{BlCa}$, where increase of size 1 in the average number of cigarettes per day increases the risk by 2 percent. This association was stronger in Guilan (P9) and Semnan (P26) with an increase of almost 5\% per each increase in the number of daily smoked cigarettes. The results can be stated as an average reduction of 5 cigarettes per day is associated with a reduction of almost $10 \%$ in the risk of BlCa.

The protective effect of fruit consumption on BlCa is not clear. Like smoking, the evidence from prospective studies for the protective effect of fruit consumption is weaker than those from case-controls (34). Some studies conclude that fruit and vegetable intakes are not likely to be associated with BlCa risk (35). However, there is a sizable body of literature that claims a protective effect for fruits. In a meta-analysis, BlCa relative risk was estimated to be 0.8 (95\% CI: $0.7-1.0$ ) for high levels of fruit consumption (36). In a cohort of atomic bomb survivors in Japan, RR was found to be 0.50 (95\% CI: $0.30-0.81$ ) for those consuming fruit 2 - 4 times per week compared to those consuming once a week or less (37). It has been suggested that fruit 
A

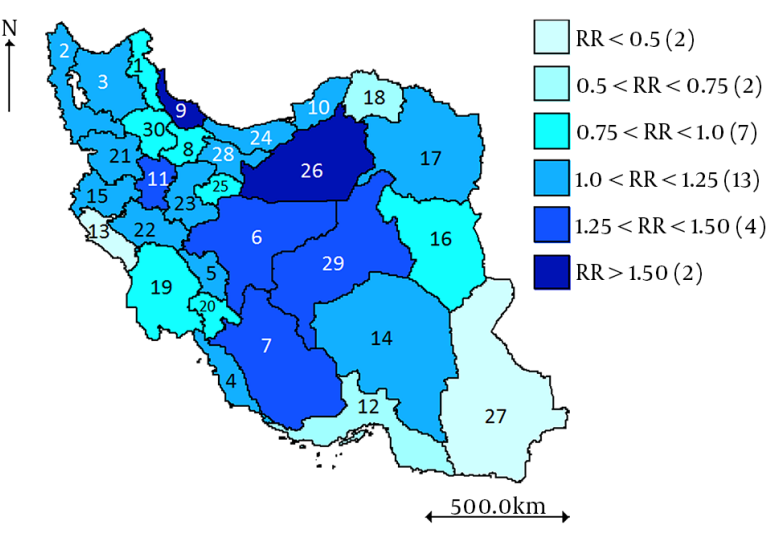

B

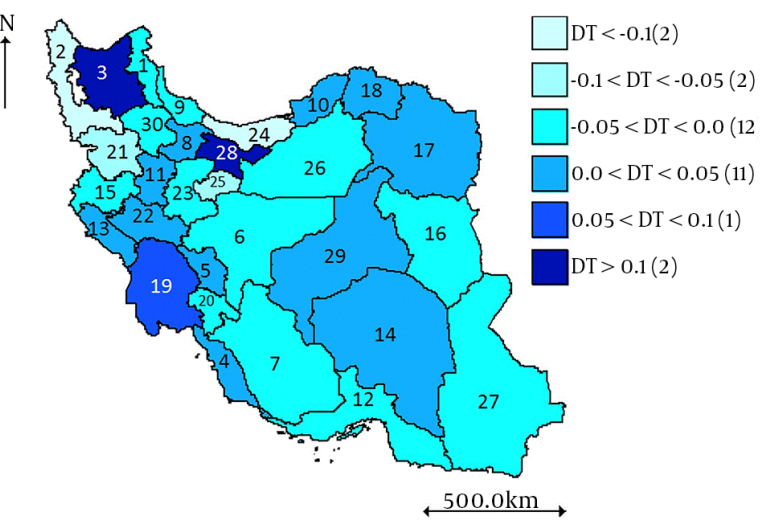

C

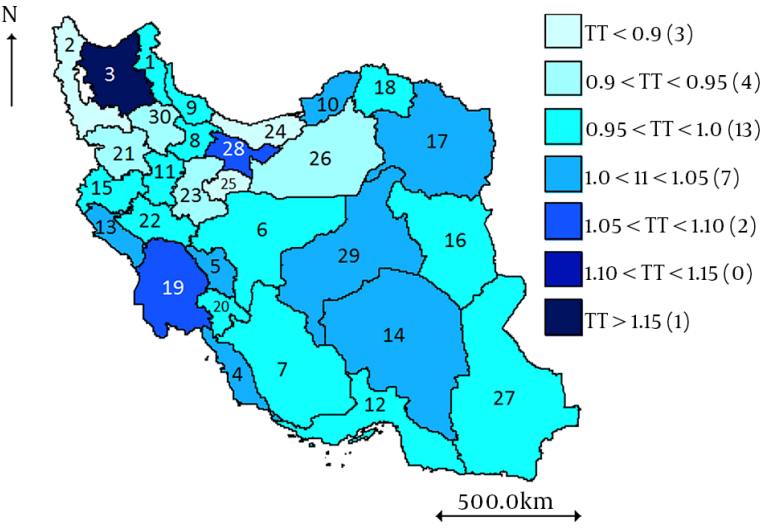

Note: Numbers in parentheses are the count of provinces in the corresponding category.

Table 2. Summary of Risk Factors Described as Mean (SD; Min, Max) for $2006-2008^{\mathrm{a}}$

\begin{tabular}{|c|c|c|c|c|c|}
\hline Year & BMI $>25$ & Cigarette & Fruit & Vegetables & Low activity \\
\hline 2006 & $43.28(6.65 ; 29.46,54.98)$ & $11.94(1.92 ; 7.53,15.08)$ & $1.13(0.24 ; 0.65,1.64)$ & $1.25(0.38 ; 0.71,2.51)$ & $30.67(7.46 ; 18.13,44.81)$ \\
\hline 2007 & $44.59(6.18 ; 28.20,55.35)$ & $12.75(1.74 ; 10.20,15.50)$ & $1.32(0.27 ; 0.80,1.95)$ & $1.38(0.42 ; 0.60,2.65)$ & $34.88(8.38 ; 16.65,51.20)$ \\
\hline 2008 & $42.99(4.93 ; 29.77,53.85)$ & $11.64(1.94 ; 8.89,16.68)$ & $1.42(0.40 ; 0.91,2.52)$ & $1.41(0.44 ; 0.78,2.85)$ & $38.30(8.15 ; 21.57,53.75)$ \\
\hline
\end{tabular}

${ }^{\mathrm{a}}$ BMI > 25: population proportion with body mass index > 25; cigarette: number of cigarettes per day; fruit: units of fruit consumption per day; vegetables: units of vegetable consumption per day; low activity: population proportion with low levels of activity.

consumption may decrease the risk of BlCa in smokers (38). To test this assumption, we included an interaction term to the model and found no significant interaction. Unicovariate model supports the protective role of vegetable intake as in the population based study in Mazandaran (P24) (39). But this association seems to be dominated by fruit consumption.

Our results indicate that 1-unit increase in average daily fruit consumption is associated with a reduction of the risk by almost $20 \%$. In provincial level, one could infer that $25 \%$ increase in current daily fruit consumption would decrease BlCa risk by $30 \%$ in Sistan and Baluchestan (P27), 20\% in Ilam (P13), and 15\% in Hormozgan (P12) and North Khorasan (P18).

We also found no significant association between BMI and physical activity levels and BlCa risk as several studies 


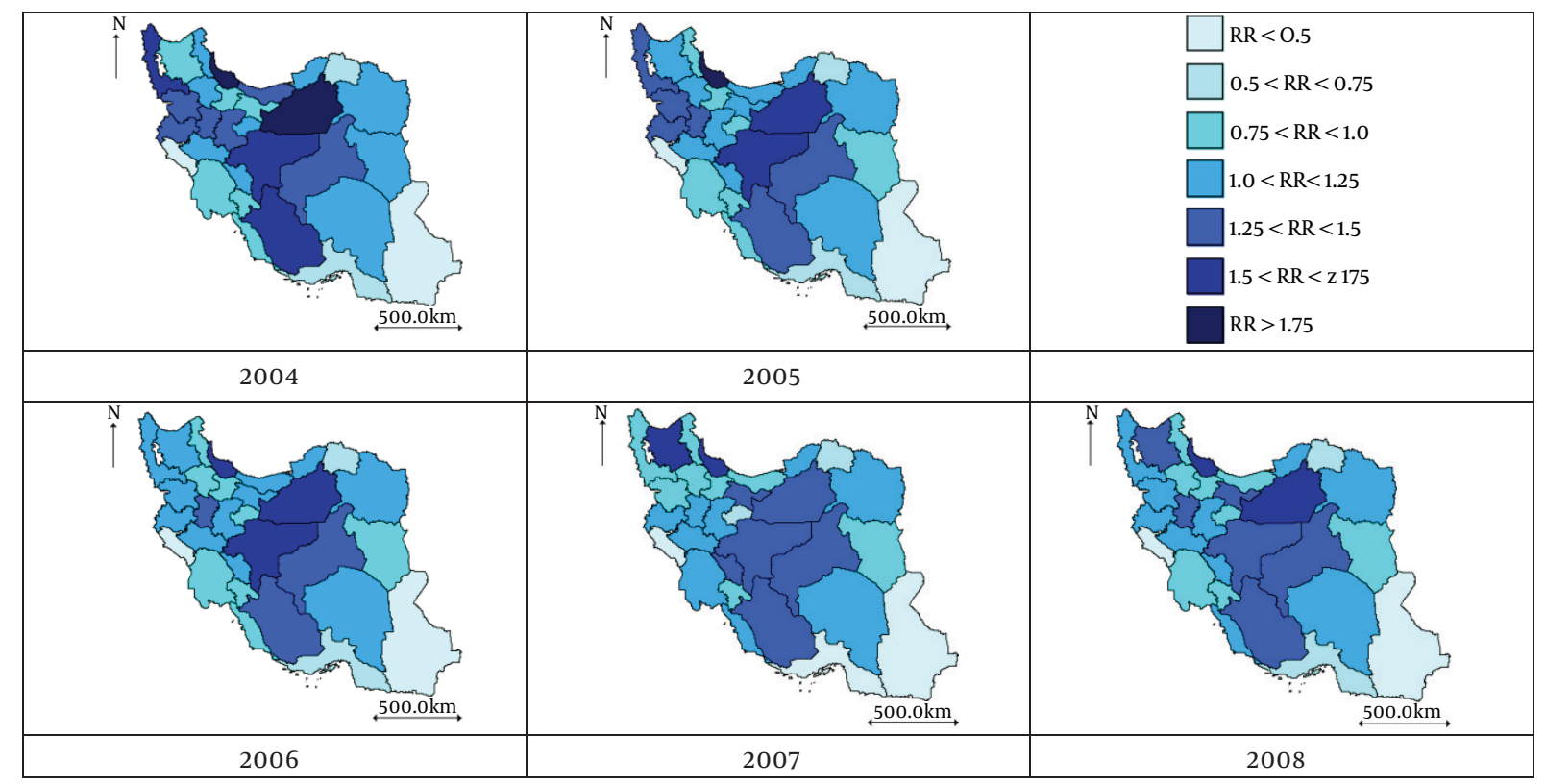

Figure 2. RR for 2004 - 2008 Estimated from Spatiotemporal Model

Table 3. Results for Uni-Covariate Spatiotemporal Models, 2006 - 2008 Described as Estimate (95\% CrI $)^{\mathrm{a}}$

\begin{tabular}{|c|c|c|c|c|c|}
\hline & BMI $>25$ & Cigarette & Fruit & Vegetables & Low Activity \\
\hline Intercept & $0.056(-0.227,0.342)$ & $-0.389^{b}(-0.634,-0.145)$ & $0.133(-0.043,0.309)$ & $-0.010(-0.163,0.140)$ & $-0.352^{\mathrm{b}}(-0.555,-0.152)$ \\
\hline$\beta$ & $-0.004(-0.010,0.001)$ & $0.021^{\mathrm{b}}(0.004,0.037)$ & $-0.207^{\mathrm{b}}(-0.300,-0.115)$ & $-0.091^{\mathrm{b}}(-0.147,-0.035)$ & $0.006^{\mathrm{b}}(0.002,0.010)$ \\
\hline Time & $-0.089^{\mathrm{b}}(-0.120,-0.058)$ & $-0.083^{\mathrm{b}}(-0.115,-0.052)$ & $-0.060^{\mathrm{b}}(-0.094,-0.027)$ & $-0.082^{\mathrm{b}}(-0.113,-0.051)$ & $-0.111^{\mathrm{b}}(-0.146,-0.077)$ \\
\hline Mean Dev. & 919.79 & 915.74 & 900.35 & 912.29 & 916.88 \\
\hline pD & 54.37 & 54.37 & 54.94 & 54.47 & 53.81 \\
\hline LS & 7.21 & 7.07 & 6.94 & 7.07 & 7.11 \\
\hline
\end{tabular}

${ }^{\mathrm{a}}$ BMI > 25: population proportion with body mass index > 25; cigarette: number of cigarettes per day; fruit: units of fruit consumption per day; vegetables: units of vegetable consumption per day; low activity: population proportion with low levels of activity, $\beta$, coefficient of the corresponding variable.

${ }^{\mathrm{b}}$ Significant at $95 \%$ level.

claim against this association (40).

However, there are some limitations to our study. Separate data for Alborz, a newly established province, was not available and it was studied as a part of Tehran (P28). The availability and estimates on risk factors are based on rather small sample sizes from each province. Hence the results may not be fully trusted. We neither assessed nor adjusted our results for some dietary and environmental factors such as water intake and source, coffee and alcohol consumption, fat intake, urinary tract diseases, and industrial or occupational chemicals. Conducting a similar study at national level would result in smoother maps and estimates in smaller regions. Adding information from more recent years, not available now, will give a more upto-date picture of the disease in Iran.

As an ecological study, the results may depend on the selection of spatial unit, a phenomenon known as ecological fallacy. That is, the relations found in this study may not exactly be the same at individual level, and caution has to be taken when drawing conclusions. However, ecological fallacy should not be an issue if, as in our study, different levels of exposure are expected to be present in all areas (21). Hence, the results could be basically generalized to individual level. Furthermore, this study provides useful information, on areas and factors requiring more attention, for governors and policy makers to improve commu- 
Table 4. Results for Multi-Covariate Spatiotemporal Models, 2006 - 2008 Described as Estimate (95\% CrI $)^{\mathrm{a}}$

\begin{tabular}{lcc}
\hline & Full Model & Best Model \\
\hline Intercept & $-0.210(-0.605,0.185)$ & $-0.126(-0.397,0.143)^{\mathrm{b}}$ \\
\hline Time & $-0.063(-0.106,-0.019)^{\mathrm{b}}$ & $-0.056(-0.090,-0.023)^{\mathrm{b}}$ \\
\hline BMI $>$ 25 & $0.000(-0.007,0.008)$ & \\
\hline Cigarette & $0.020(0.002,0.038)^{\mathrm{b}}$ & $0.021(0.004,0.038)^{\mathrm{b}}$ \\
\hline Fruit & $-0.223(-0.394,-0.052)^{\mathrm{b}}$ & $-0.208(-0.301,-0.116)^{\mathrm{b}}$ \\
Vegetables & $0.022(-0.071,0.116)$ & \\
\hline Low activity & $0.001(-0.002,0.006)$ & 893.75 \\
Mean Dev. & 896.53 & 949.70 \\
\hline DIC & 955.10 & 55.94 \\
\hline pD & 58.57 & 6.89 \\
\hline LS & 7.04 & \\
\hline
\end{tabular}

${ }^{\mathrm{a}} \mathrm{BMI}>25$ : population proportion with body mass index $>25$; cigarette: number of cigarettes per day; fruit: units of fruit consumption per day; vegetables: units of vegetable consumption per day; low activity: population proportion with low levels of activity.

${ }^{\mathrm{b}}$ Significant at $95 \%$ level.

nity health.

In conclusion, this ecological study confirms previous findings about the role of smoking in increasing the risk of BlCa. This association was present after adjustments for the other major factors. Whilst the effect of other factors were not confirmed, the results provide further evidence on the effect of fruit consumption as a protective factor in developing BlCa. However, the results show that the risk of BlCa has been decreasing in Iran during 2004 - 2008, yet $64 \%$ of province have increasing risk, $47 \%$ of which have a trend steeper than country average trend. More attention needs to be drawn to Tehran, East Azarbayjan, Semnan and Ghilan provinces.

\section{Acknowledgments}

None.

\section{Footnotes}

Authors' Contribution: Tohid Jafari-Koshki performed the analyses and prepared the initial draft of the manuscript. Shahram Arsang-Jang participated in literature review and discussion. Behzad Mahaki participated in the data acquisition, design and the analysis. All authors read and approved the final manuscript.

Fundding/Support: Non declared.

Conflict of Interest: The authors declare that there are no conflicts of interest.

\section{References}

1. Fouladi N, Pourfarzi F, Amani F, Ali-Mohammadi H, Lotf I, Mazaheri E. Breast cancer in Ardabil province in the north-west of Iran: an epidemiological study. Asian Pac J Cancer Prev. 2012;13(4):1543-5. [PubMed: 22799363].

2. Ferlay J, Soerjomataram I, Ervik M DR, Eser S, Mathers C. Cancer Incidence and Mortality Worldwide Lyon, France International Agency for Research on Cancer; 2013. Available from: http://globocan.iarc.fr.

3. Akbari ME, Hosseini SJ, Rezaee A, Hosseini MM, Rezaee I, Sheikhvatan M. Incidence of genitourinary cancers in the Islamic Republic of Iran: a survey in 2005. Asian Pac J Cancer Prev. 2008;9(4):549-52. [PubMed: 19256736].

4. Svatek RS, Hollenbeck BK, Holmang S, Lee R, Kim SP, Stenzl A, et al. The economics of bladder cancer: costs and considerations of caring for this disease. Eur Urol. 2014;66(2):253-62. doi: 10.1016/j.eururo.2014.01.006. [PubMed: 24472711].

5. Simons MP, Nauseef WM, Griffith TS. Neutrophils and TRAIL: insights into BCG immunotherapy for bladder cancer. Immunol Res. 2007;39(13):79-93. [PubMed: 17917057].

6. Brennan P, Bogillot O, Cordier S, Greiser E, Schill W, Vineis P, et al Cigarette smoking and bladder cancer in men: a pooled analysis of 11 case-control studies. Int J Cancer. 2000;86(2):289-94. [PubMed: 10738259].

7. Jankovic S, Radosavljevic V. Risk factors for bladder cancer. Tumori. 2007;93(1):4-12. [PubMed: 17455864].

8. Buchner FL, Bueno-de-Mesquita HB, Ros MM, Kampman E, Egevad $\mathrm{L}$, Overvad $\mathrm{K}$, et al. Variety in vegetable and fruit consumption and risk of bladder cancer in the European Prospective Investigation into Cancer and Nutrition. Int J Cancer. 2011;128(12):2971-9. doi: 10.1002/ijc.25636. [PubMed: 20979109].

9. Larsson SC, Andersson SO, Johansson JE, Wolk A. Diabetes mellitus, body size and bladder cancer risk in a prospective study of Swedish men.EurJCancer. 2008;44(17):2655-60. doi:10.1016/j.ejca.2008.07.012. [PubMed: 18707871].

10. Gilks WR, Richardson S, Spiegelhalter DJ. Markov Chain Monte Carlo in Practice. London: Chapman \& Hall/CRC; 1996.

11. Jafari-Koshki T, Schmid VJ, Mahaki B. Trends of breast cancer incidence in Iran during 2004-2008: a Bayesian space-time model. Asian Pac J Cancer Prev. 2014;15(4):1557-61. [PubMed: 24641367].

12. Jafari-Koshki T, Arsang-Jang S, Raei M. Applying spatiotemporal models to study risk of smear-positive tuberculosis in Iran, 2001-2012. Int J Tuberc Lung Dis. 2015;19(4):469-74. doi: 10.5588/ijtld.14.0459. [PubMed: 25860004].

13. Rastaghi S, Jafari-Koshki T, Mahaki B. Application of Bayesian Multilevel Space-Time Models to Study Relative Risk of Esophageal Cancer in Iran 2005-2007 at a County Level. Asian Pac J Cancer Prev. 2015;16(14):5787-92.

14. Haddad-Khoshkar A, Jafari-Koshki T, Mahaki B. Investigating the Incidence of Prostate Cancer in Iran 2005 -2008 using Bayesian Spatial Ecological Regression Models. Asian Pac JCancer Prev. 2015;16(14):591721

15. Mahaki B, Mehrabi Y, Kavousi A, Akbari MA, Waldhoer T, Schmid VJ, Yaseri M. Multivariate Disease Mapping of Seven Prevalent Cancers in Iran using a Shared Component Model. Asian Pac J Cancer Prev. 2011;12:2353-8. [PubMed: 22296383].

16. Asmarian N, Jafari-Koshki T, Soleimani A, Ayatollahi SMT. Area-to-Area Poisson Kriging and Spatial Bayesian Analysis in Mapping of Gastric Cancer Incidence in Iran. Asian Pac J Cancer Prev.. 2016;17(10):4587-90.

17. Asmarian N, Ruzitalab A, Kavousi A, Salehi M, Mahaki B. Area-to-Area Poisson Kriging Analysis of Mapping of County-Level Esophageal Cancer Incidence Rates in Iran. Asian Pac J Cancer Prev. 2013;14(1):11-13. 
18. Haddad-Khoshkar A, Jafari-Koshki T, Mahaki B. Comparison of Bayesian Spatial Ecological Regression Models for Investigating the Incidence of Breast Cancer in Iran, 2005-2008. Asian Pac J Cancer Prev. 2015;16(14):5669-73. [PubMed: 26320433].

19. Bernardinelli L, Clayton D, Pascutto C, Montomoli C, Ghislandi M, Songini M. Bayesian analysis of space-time variation in disease risk. Stat Med. 1995;14(21-22):2433-43. [PubMed: 8711279].

20. Morgenstern H. Ecologic studies in epidemiology: concepts, principles, and methods. Annu Rev Public Health. 1995;16:61-81. doi: 10.1146/annurev.pu.16.050195.000425. [PubMed: 7639884].

21. Portnov BA, Dubnov J, Barchana M. On ecological fallacy, assessment errors stemming from misguided variable selection, and the effect of aggregation on the outcome of epidemiological study. J Expo Sci Environ Epidemiol. 2007;17(1):106-21. doi: 10.1038/sj.jes.7500533. [PubMed: 17033679].

22. Farahmand M, Khademolhosseini F, Medhati M, Shokrpour N, Joulaei $\mathrm{H}$, Mehrabani D. Trend of bladder cancer in Fars province, southern Iran, 2002-2006. Iran Red Crescent Med J. 2009;2009(4):470-2.

23. Aminian O, Saburi A, Mohseni H, Akbari H, Chavoshi F, Akbari H. Occupational risk of bladder cancer among Iranian male workers. Urol Ann. 2014;6(2):135-8. doi: 10.4103/0974-7796.130643. [PubMed: 24833825].

24. Besag J, York J, Molli A. Bayesian image restoration, with two applications in spatial statistics. Ann Inst Statistic Math. 1991;43(1):1-20. doi: 10.1007/bf00116466.

25. Faldini C, Leonetti D, Nanni M, Di Martino A, Denaro L, Denaro V, et al. Cervical disc herniation and cervical spondylosis surgically treated by Cloward procedure: a 10-year-minimum follow-up study. J Orthop Traumatol. 2010;11(2):99-103. doi: 10.1007/s10195-010-0093-z. [PubMed: 20532943].

26. Rue H, Martino S, Chopin N. Approximate Bayesian inference for latent Gaussian models by using integrated nested Laplace approximations. J Royal Statistic Soc Series B Statistic Methodol. 2009;71(2):319-92. doi: 10.1111/j.1467-9868.2008.00700.x.

27. Schrödle B, Held L. A primer on disease mapping and ecological regression using \$\$\{|texttt\{INLA\}\}\$. Comput Statistics. 2010;26(2):24158. doi: 10.1007/s00180-010-0208-2.

28. Negri E, La Vecchia C. Epidemiology and prevention of bladder cancer. Eur J Cancer Prev. 2001;10(1):7-14. [PubMed: 11263594].

29. Chiu BC, Lynch CF, Cerhan JR, Cantor KP. Cigarette smoking and risk of bladder, pancreas, kidney, and colorectal cancers in Iowa. Ann Epidemiol. 2001;11(1):28-37. [PubMed: 11164117].
30. Pelucchi C, La Vecchia C, Negri E, Dal Maso L, Franceschi S. Smoking and other risk factors for bladder cancer in women. Prev Med. 2002;35(2):114-20. [PubMed: 12200095].

31. Bjerregaard BK, Raaschou-Nielsen O, Sorensen M, Frederiksen K, Christensen J, Tjonneland A, et al. Tobacco smoke and bladder cancerin the European Prospective Investigation into Cancer and Nutrition. Int J Cancer. 2006;119(10):2412-6. doi: 10.1002/ijc.22169. [PubMed: 16894557].

32. Freedman ND, Silverman DT, Hollenbeck AR, Schatzkin A, Abnet CC. Association between smoking and risk of bladder cancer among men and women. JAMA. 2011;306(7):737-45. doi: 10.1001/jama.2011.1142. [PubMed: 21846855].

33. Shakhssalim N, Hosseini SY, Basiri A, Eshrati B, Mazaheri M, Soleimanirahbar A. Prominent bladder cancer risk factors in Iran. Asian Pac J Cancer Prev. 2010;11(3):601-6. [PubMed: 21039023].

34. Riboli E, Norat T. Epidemiologic evidence of the protective effect of fruit and vegetables on cancer risk. Am J Clin Nutr. 2003;78(3 Suppl):559S-69S. [PubMed:12936950].

35. Michaud DS, Pietinen P, Taylor PR, Virtanen M, Virtamo J, Albanes D. Intakes of fruits and vegetables, carotenoids and vitamins A, E, C in relation to the risk of bladder cancer in the ATBC cohort study. Br J Cancer. 2002;87(9):960-5. doi: 10.1038/sj.bjc.6600604. [PubMed: 12434284].

36. Steinmaus CM, Nunez S, Smith AH. Diet and bladder cancer: a metaanalysis of six dietary variables. Am J Epidemiol. 2000;151(7):693-702. [PubMed: 10752797].

37. Nagano J, Kono S, Preston DL, Moriwaki H, Sharp GB, Koyama K, et al. Bladder-cancer incidence in relation to vegetable and fruit consumption: a prospective study of atomic-bomb survivors. Int J Cancer. 2000;86(1):132-8. [PubMed: 10728607].

38. Kellen E, Zeegers M, Paulussen A, Van Dongen M, Buntinx F. Fruit consumption reduces the effect of smoking on bladder cancer risk. The Belgian case control study on bladder cancer. Int J Cancer. 2006;118(10):2572-8. doi:10.1002/ijc.21714. [PubMed:16380991].

39. Ahmadi M, Ranjbaran H, Amiri MM, Nozari J, Mirzajani MR, Azadbakht M, et al. Epidemiologic and socioeconomic status of bladder cancer in Mazandaran Province, northern Iran. Asian Pac J Cancer Prev. 2012;13(10):5053-6. [PubMed: 23244109].

40. Koebnick C, Michaud D, Moore SC, Park Y, Hollenbeck A, BallardBarbash R, et al. Body mass index, physical activity, and bladder cancer in a large prospective study. Cancer Epidemiol Biomarkers Prev. 2008;17(5):1214-21. doi: 10.1158/1055-9965.EPI-08-0026. [PubMed: 18483344]. 